\title{
Original Article \\ From traditional to contemporary: Revelations in Chinese garden and public space design
}

\author{
Bo Yang ${ }^{\mathrm{a}, *}$ and Nancy J. Volkman ${ }^{\mathrm{b}}$
}

a Department of Landscape Architecture and Environmental Planning, Utah State University, 4005 Old Main Hill, Logan, Utah 84322-4005, USA.

E-mail: bo.yang@usu.edu

${ }^{\mathrm{b}}$ Department of Landscape Architecture and Urban Planning, Texas A\&M University, College Station, Texas 77843-3137, USA.

E-mail: nvolkman@archmail.tamu.edu

${ }^{*}$ Corresponding author.

\begin{abstract}
China, like many other nations, struggled in the twentieth century with defining an indigenous landscape design tradition. This was particularly true in addressing urban open space design after China implemented the Open Door Policy in the late 1970s, when Chinese garden design traditions became largely neglected. The objective of this study is to determine whether the traditional design approach could still effectively serve as modern design inspiration. Built upon a previous study by Wu (1999), our study is a reflective critique on modern Chinese urban public space design. We compare major types of traditional and modern Chinese urban open spaces. The percentage areas of five landscape variables that $\mathrm{Wu}$ proposed (planting, water, rock, architecture and pavement) were quantified using Photoshop and ArcGIS software. Although Wu (1999) compared only scholars' gardens (a traditional model) with modern parks (a modern model), we include imperial gardens (another traditional model) and urban plazas (another modern model). In addition, we supplemented Wu's plan analysis with perspective view analysis (photographs). Our results suggest more similarities between traditional and modern landscapes than previously suggested. This article concludes by suggesting that traditional models can be relevant to contemporary urban public space design in China.

URBAN DESIGN International (2010) 15, 208-220. doi:10.1057/udi.2010.13
\end{abstract}

Keywords: Chinese; traditional landscapes; modern park; modern plaza; landscape visual assessment

\section{Introduction}

As globalization has led to a homogenization in public space design, the dominance of Western traditions of landscape architecture applied in non-Western settings has been questioned. Such has been the case in China. Although European societies have at times in the past preferred large open spaces, grassed parklands and paved plazas for recreational purposes, traditional Chinese society favored the intimate scale of garden and courtyard (Boyd, 1962; Ji, 1988). There are two major subsets of traditional gardens in China: scholars' gardens (Figure 1), typically found in Jiangnan area in China (cities such as Suzhou and
Hangzhou) and imperial gardens (Figure 2), which survive today chiefly in Beijing and Chengde. ${ }^{1}$

Although public open space is not a new phenomenon in China, contemporary Chinese landscape architects continue to struggle to define an indigenous design tradition, often ending up by following Western models uncritically. This has been exemplified by the chengshi meihua yundong (City Cosmetic movement) of the past 20 years, when China emulated the relics of the American City Beautiful movement and created numerous Western-style open plazas that generated conflicts with the existing traditional urban fabric (Yu and Padua, 2007). ${ }^{2}$ 
There are generally two types of public open spaces in contemporary China - the garden or park, both referred to as yuan in Chinese, and the plaza, referred to as guangchang in Chinese

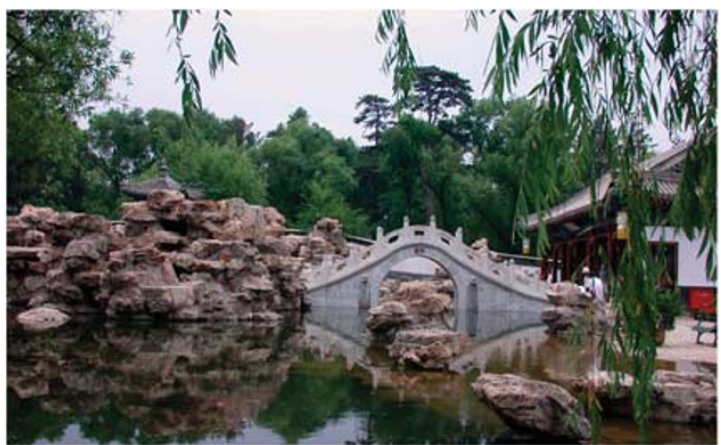

Figure 1: Example of Chinese traditional scholars' garden. Photo courtesy: Zhifang Wang.
(Foreign Language Teaching and Research Press, 1995). ${ }^{3}$ Each type follows a different design approach, with yuan having more traditional Chinese garden features and guangchang following European-inspired design ideas. The typical European-inspired design idea in China has been based on the Renaissance-Baroquestyle plaza and the later American City Beautiful movement principles ( $\mathrm{Yu}$ and $\mathrm{Li}, 2003$; $\mathrm{Yu}$ and Padua, 2007), where a symmetrical plan layout and geometric plan structures are often used. ${ }^{4}$ The key features and differences between Chinese landscape designs and RenaissanceBaroque-style designs are summarized in Table 1 (Keswick, 1978; Chung, 1982; Yang, 1982; Chen and Yu, 1986; Peng, 1986; Liu, 1993; Wong, 2001)..$^{5}$

On the one hand, China has focused on replicating large numbers of Western-style plazas

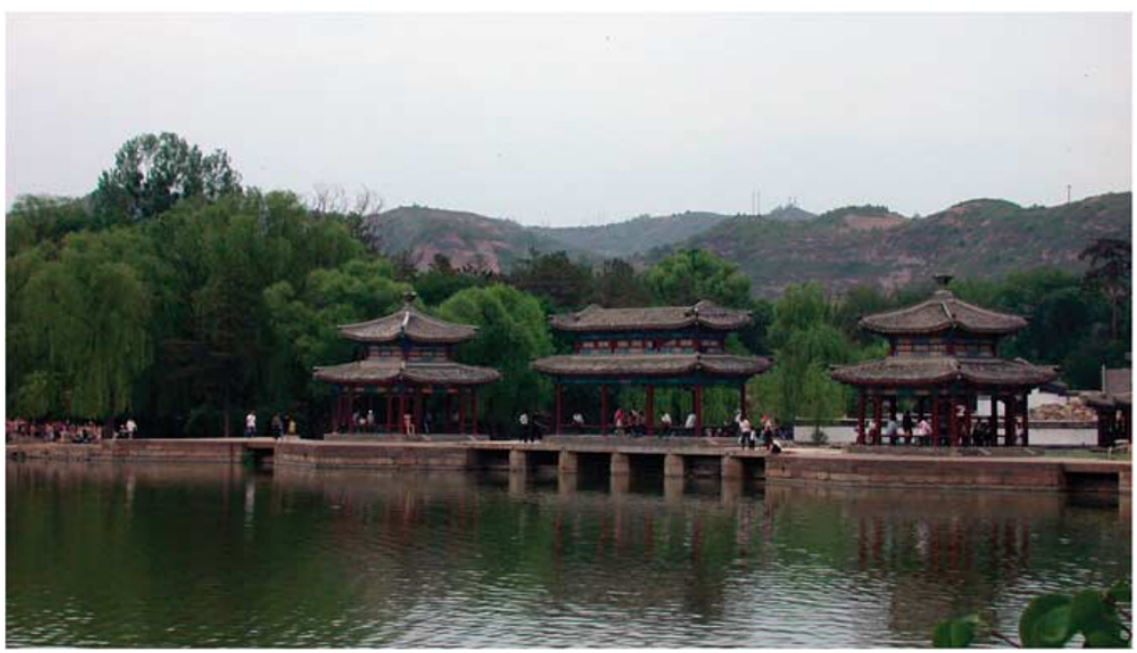

Figure 2: Example of Chinese traditional imperial garden. Summer Resort, Chengde. Photo courtesy: Zhifang Wang.

Table 1: Comparison of principle characteristics of Chinese and European-inspired approach in landscape designs

\begin{tabular}{lll}
\hline & Chinese style & European-inspired style \\
\hline $\begin{array}{ll}\text { Composition } \\
\text { View }\end{array}$ & Asymmetrical & Bilateral symmetry \\
Planting & Framed by structures in the garden & Lines of sight; views open at ground level \\
& In naturalistic groupings & In rectilinear arrangements; expansive lawn; geometric \\
patterned plantings & Rarely used, except in carved form \\
Rock & Used as sculpture and to define water edge & Dominate the view; often focal point on axis \\
Building & Integrated with garden & Rectilinear shape \\
Water & Naturalistic shape & Often linear \\
Pavement & Often circuitous &
\end{tabular}

Note: The Chinese style represents the features found in the traditional models, the scholars' garden and imperial garden, and one of the modern models, the urban park. The European-inspired style shows the other modern model, the urban plaza. Urban plaza design in China is largely influenced by the Renaissance-Baroque style design inspiration and later by the American City Beautiful movement. The urban plaza model, usually presents a grandiose plane layout, is perhaps the mostly mimicked European design approach in China. 


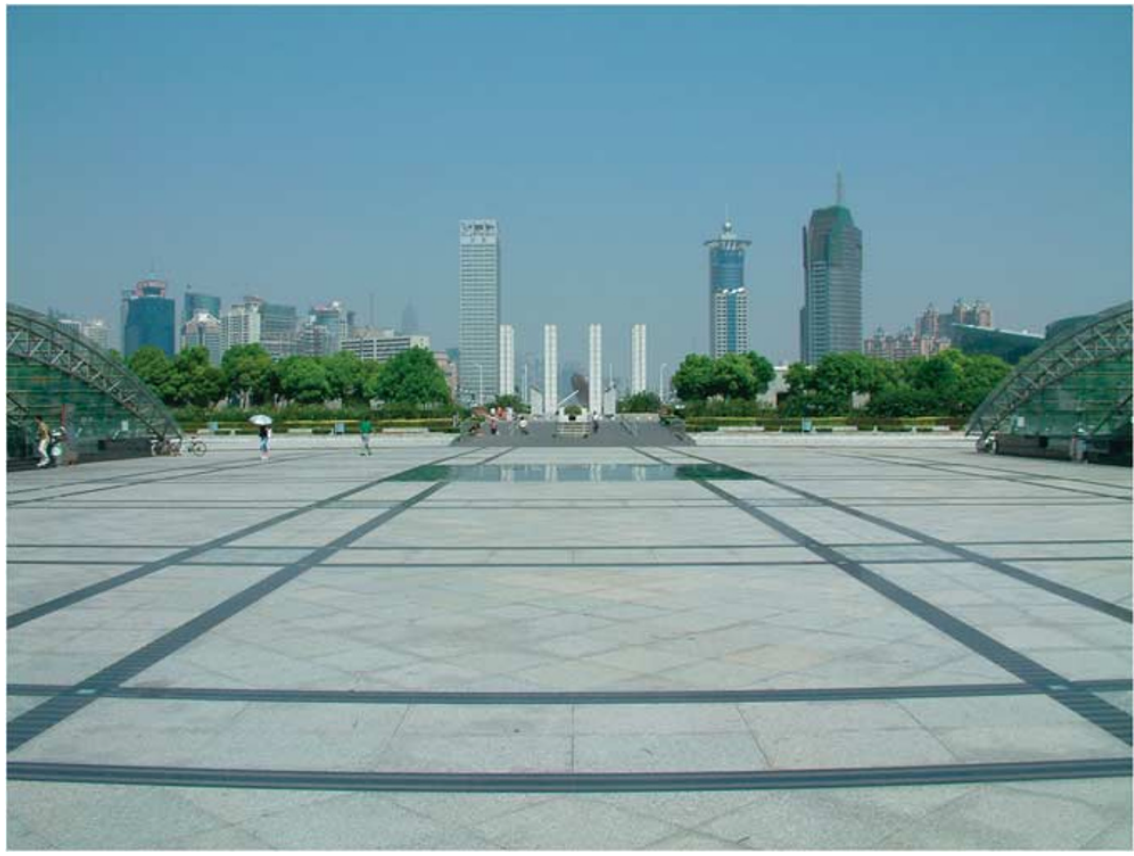

Figure 3: Century Plaza in Shanghai. Photo courtesy: Xuemei Zhu.

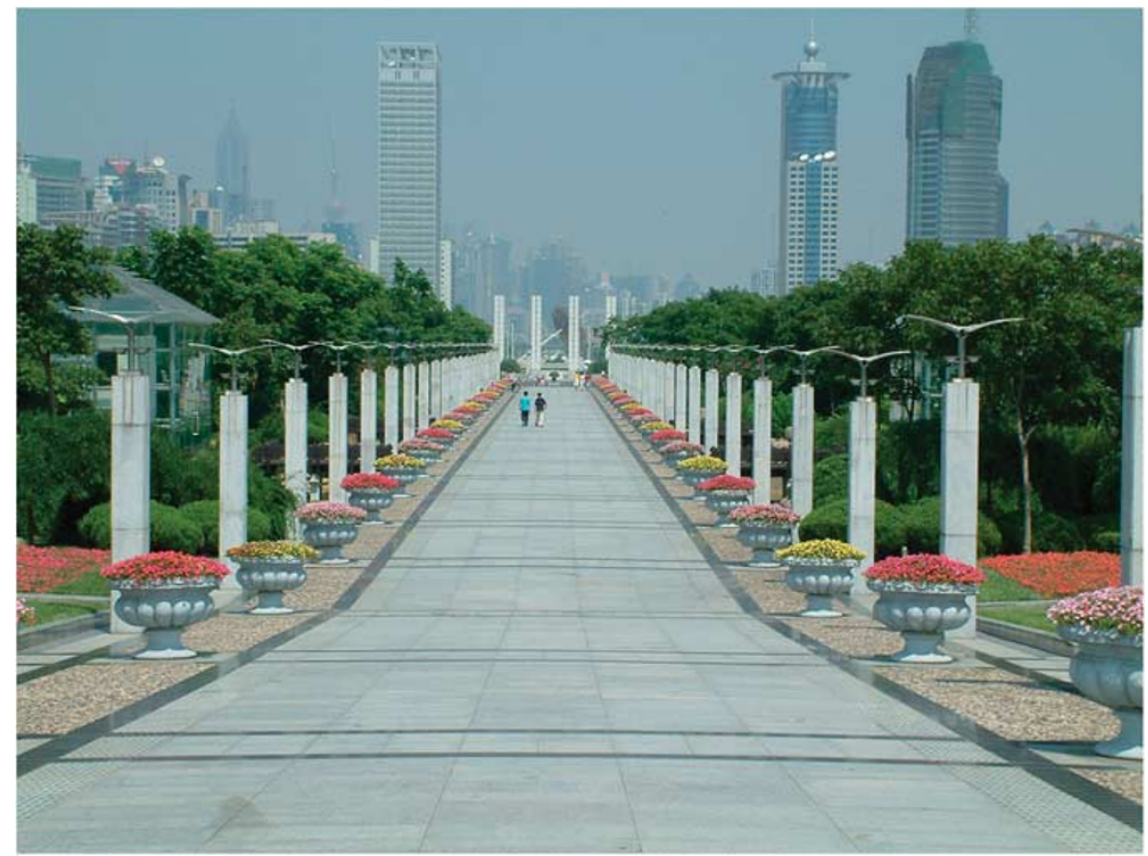

Figure 4: Century Plaza in Shanghai. Photo courtesy: Xuemei Zhu.

and boulevards in its recent urban design efforts (Figures 3 and 4); on the other hand, China's garden legacy is vanishing at an alarming speed (Morris, 1983). The exquisite courtyard system has by and large been abandoned and even devastatingly destroyed in many Chinese cities when new construction occurred (Morris, 1983).
Suzhou, where most remaining scholars' gardens are located, was reported to have only 23 gardens remaining intact in the historic sites registration of 1982. However, 142 scholars' gardens had been identified before 1949. While some gardens could be restored, 96 gardens were entirely destroyed (Suzhou Local History Academy, 1995). 


\section{Scholarly critique of Western-style design inspiration}

Western-style plazas did not enter China accidentally. After the Open Door Policy was implemented at the end of the 1970s, hundreds of mayors and municipal officials visited the West to study urban development ( $\mathrm{Yu}$ and $\mathrm{Li}, 2003 ; \mathrm{Yu}$ and Padua, 2007). ${ }^{6}$ What impressed the Chinese officials most were the grandiose central axes and manicured lawns of many European and American parks (Yu and Padua, 2007). To match the officials' ambitions for urban development schemes, exceedingly large Renaissance-Baroquestyle ceremonial plazas and overly wide boulevards were replicated all over China. Conflicts, however, were inevitably created between these Western-style urban open space patterns and the traditional courtyard-dominant residential communities in China (Wu, L., 1996; Geng, 1999; Yu and Padua, 2007).

As Chinese scholars have questioned this Western-inspired open space design approach, research has been conducted to explore the variations between traditional Chinese landscape design and that from the West, in part to investigate the potential use of the traditional garden design legacy in modern open spaces (Dillingham, 1991; Wu, 1999; Cheng, 2003; Zhou, 2004). Some scholars argued that traditional gardens only served the privileged few who enjoyed a slow, pampered pace of life (for example, emperors and prominent officials), whereas modern public open space should serve the general public for daily recreational purposes. Other scholars contend that to restore the primacy of the traditional Chinese garden legacy, it is essential to integrate traditional design principles with modern needs $(\mathrm{Wu}, \mathrm{W}$., 1996; Wu, 1999; Chen, 1999).

One of the more influential early quantitative studies in this area was conducted by Wu (1999). This study compared five pairs of traditional gardens and modern parks. Wu determined that there were vast differences between traditional gardens and modern park designs in the percentage surface area of five key landscape elements she examined - water, rock, pavement, building and planting. She further concluded that the traditional models were so different from what the modern urban landscape required that it would be difficult to incorporate traditional models into modern public open space design. On the basis of the authors' experiences in
Chinese gardens, both traditional garden models suggest visual similarities with the modern park model. Plazas, however, present a distinct look from the traditional models. In addition, traditional gardens and modern parks are usually designed naturalistically. This is different from the Renaissance-Baroque-style plazas, where visitors usually can view the entire plaza at a glance.

Therefore, we hypothesized that there was a traditional Chinese model - the imperial garden that could serve modern needs because of its scale and variety of land uses. In addition, we hypothesized that there were fewer differences between traditional and modern designs than previously concluded, particularly by Wu. Finally, we suspected that Wu's choice of plans for analysis may have affected her results, and we suggested using perspective views as an additional form of analysis.

\section{Traditional Chinese garden design: Plan versus perspective views}

We added perspective views in analysis because such views were the starting point in Chinese garden design, influenced as it was by painting (Ji, 1988). Traditional Chinese arts, mountainand-water painting in particular, exerted a great influence on garden designs (Keswick, 1978). Noted design techniques such as Borrowed Landscape and View Framing were influenced by the painting arts (Thacker, 1979; Yang, 1982; Sun, 1986; Liu, 1993). Cheng Ji's Craft of Gardens (1988) summarizes the body of theories and design techniques in Chinese garden design, in which design typically started with three-dimensional perspective paintings. Designers orchestrate the space to provide diverse visual effects and manipulate visitors' feelings. Plans, however, often follow and evolve as a result of the views that are created (Peng, 1986; Ji, 1988; Liu, 1993).

As a result, the Chinese garden design approach contrasts with much RenaissanceBaroque-style design in which a structured plan form is the starting point for spatial organization while views were considered later (Newton, 1971; Gothein, 1979; Thacker, 1979). On the basis of the purpose and sequence of traditional Chinese open space design, it is logical that analysis of views would give a better sense of the design intent of both traditional and modern models. In addition, as plazas tend to emphasize ground 
plane pattern more than parks do, it is hypothesized that parks would more closely follow the design elements found in traditional models than would plazas.

\section{Study Sites}

Our sample sites were chosen from cities that either have traditional gardens or significant contemporary open spaces. We used five cases for each of the four site categories to compensate for idiosyncratic characteristics of any one site. ${ }^{7}$ For scholars' gardens, we chose all the five examples from the Jiangnan area (Ji, 1988) simply because it is home to many scholars' gardens. For imperial gardens, the selection was much more limited than for the other three categories, because fewer of these were built or have survived (Cheng, 1998b). For modern parks and modern plazas, we selected cases from major Chinese cities, for example, Shanghai, Wuhan and Guangzhou (Xie and Costa, 1993). After the Second Opium War period (1856-1860), these cities were the first to be exposed to Western influences, including design ideas. Huang-Pu
Park in Shanghai, for example, was the first modern park built in China (1868) and may have been designed by a European landscape architect.

Site scale was another consideration. A largescale park or garden may have substantially more water than some small spaces. Our samples ranged from small pocket parks to large urban central parks and plazas. The smallest site we chose was a downtown mini-park of $1200 \mathrm{~m}^{2}(0.3$ acre) in Wuhan. The largest site we used was the Chengde Resort, a $5600000 \mathrm{~m}^{2}$ (1384 acres) imperial garden $200 \mathrm{~km}$ (125 miles) north of Beijing. The names and basic data for the 19 study sites are presented in Table 2 and Figure 5.

\section{Objective and Hypotheses}

The objective of our study was to determine whether traditional models were still valid design inspirations for contemporary designs in China. Three hypotheses were investigated: (1) there are fewer differences between traditional and modern designs than $\mathrm{Wu}$ had concluded; (2) there is a traditional Chinese model (imperial garden) that could be used to serve modern needs; and

Table 2: Study sites: (1) traditional scholars' garden (small yuan), (2) traditional imperial garden (very large yuan), (3) modern park (yuan) and (4) modern plaza (guangchang)

\begin{tabular}{|c|c|c|c|c|}
\hline Type & Name & Date & Place & Area $\left(m^{2}\right)$ \\
\hline \multirow[t]{4}{*}{ Imperial garden $^{a}$} & Summer Palace & 18th century & Beijing & 2900000 \\
\hline & The North Sea & 10th century & Beijing & 70000 \\
\hline & $\begin{array}{l}\text { Garden of Perfection and } \\
\text { Brightness }\end{array}$ & 18th century & Beijing & 3500000 \\
\hline & Summer Resort at Chengde & 18th century & Chengde, Hebei Province & 5600000 \\
\hline \multirow[t]{5}{*}{ Scholars' garden } & Humble Administrator's Garden & 16th century & Suzhou, Jiangsu Province & 50000 \\
\hline & Lingering Garden & 16th century & Suzhou, Jiangsu Province & 30000 \\
\hline & Ge Yuan Garden & 19th century & Yangzhou, Jiangsu Province & 20000 \\
\hline & Yi Pu Garden & 16th century & Suzhou, Jiangsu Province & 1800 \\
\hline & Ji Chang Yuan & 16th century & Wuxi, Jiangsu Province & 9900 \\
\hline \multirow[t]{5}{*}{ Urban Plaza } & Cheng Jia Ci Plaza & 1980s-1990s & $\begin{array}{l}\text { Guangzhou, Guangdong } \\
\text { Province }\end{array}$ & 5700 \\
\hline & Hong Shan Plaza & c. 2000 & Wuhan, Hubei Province & 108000 \\
\hline & Nanjing Rd Plaza & c. 1980 & Wuhan, Hubei Province & 1200 \\
\hline & Xibei Lake Plaza & 1998 & Wuhan, Hubei Province & 16000 \\
\hline & People's Square & 1994 & Shanghai & 80000 \\
\hline \multirow[t]{5}{*}{ Urban Park } & Qing Tai Park & 1970s Renovated & Wuhan, Hubei Province & 10000 \\
\hline & Harcourt Garden & c.1975 & Hong Kong & 10700 \\
\hline & Fang Ta Park & 1978 & Shanghai & 120000 \\
\hline & Shipyard Park & c. 2000 & Zhongshan, Guangdong Province & 110000 \\
\hline & Xujiahui Park & 2001 & Shanghai & 66700 \\
\hline
\end{tabular}

${ }^{a}$ We studied only four cases for the imperial gardens because very few remain (Cheng, 1998b). 


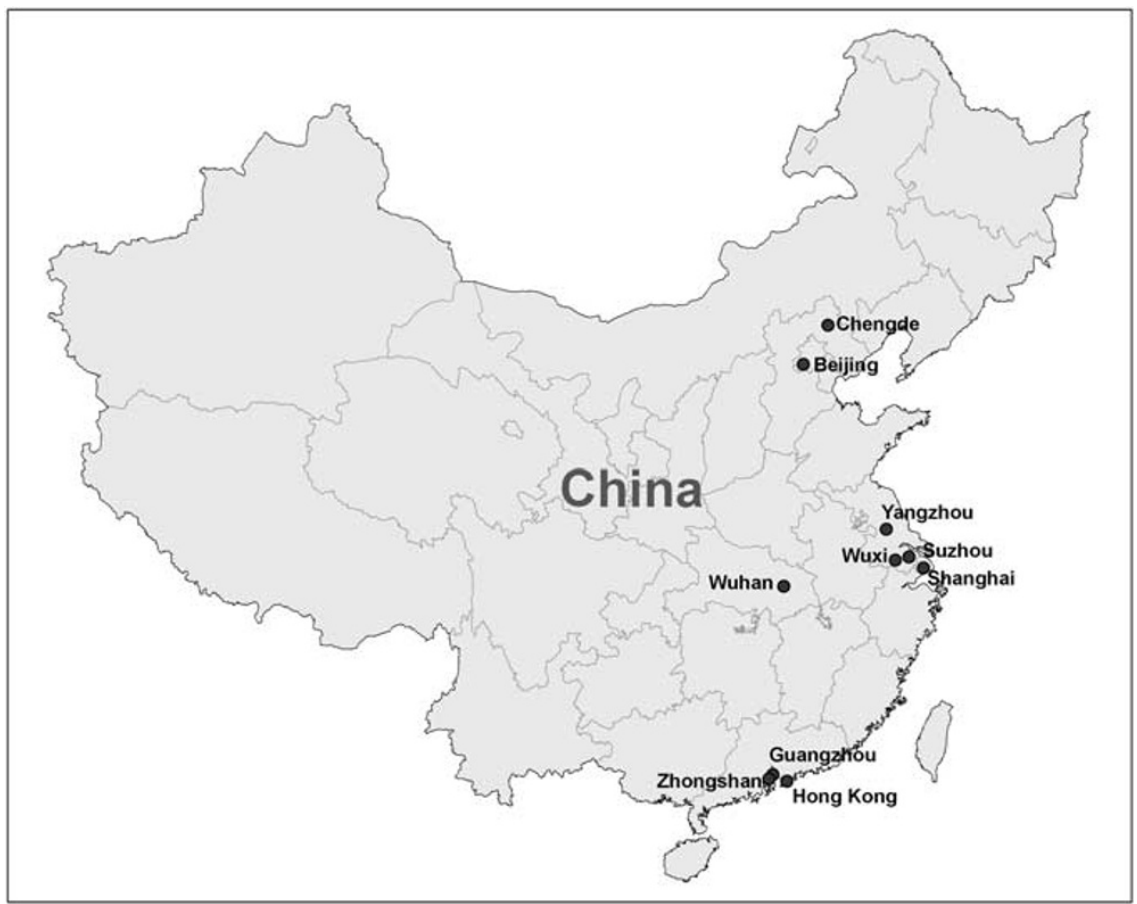

Figure 5: Study site locations.

(3) perspective views are more appropriate than plans in the visual assessments for this type of study (Zhu, 1992).

We retained the same five landscape elements that $\mathrm{Wu}$ examined. We also retained the distinction between traditional sites and modern ones, but varied the case study sites and study methods. Thus, building upon Wu's study, the following three factors were added to our study: (1) another type of traditional model, the imperial garden, was included in the sample, in addition to the scholars' garden; (2) another type of modern model, the public plaza, was included, in addition to the public park; and (3) site photographs were used to measure areas in each of the five landscape materials, in addition to measurements from two-dimensional site plans. In sum, we took Wu's (1999) research as a point of departure, but then modified the types of sites studied and the analytic method used to address what we concluded had been limitations in her work.

\section{Data and Method}

Plans were scanned from various books on gardens, parks and plazas. ${ }^{8}$ Perspective photographs were collected from authors' multiple site visits. Previous studies suggested that photographs are valid surrogates for landscape visual assessment (Shuttleworth, 1980), and that they could be used to examine various landscape components in the views (Stamps, 2001; Arriaza et al, 2004; Chen et al, 2009). Photograph samples size needs to be large enough to represent various landscape types (Shuttleworth, 1980), and a repeatable method needs to be developed for different study purposes (Clay and Marsh, 1997, 2001; Stamps, 2001; Chen et al, 2009).

\section{Viewpoint selection}

In our study, one important consideration was the best location from which to take representative photographs. Several criteria were specified in viewpoint selection and in the procedures of analyzing photographs in order to minimize the bias owing to the photographer's subjective judgment. ${ }^{9}$

The first criterion was that the photographs should be set at eye-level so that they reflect a person's experience walking through the site. In addition, photographs should best represent the whole of the site with its characteristic spaces and features, rather than a single focal element. Previous studies have used slope, landscape type 
and other site characteristics to separate the site into homogeneous sections (Leitão and Ahern, 2002; Arriaza et al, 2004). Chinese gardens, however, are rarely homogeneous in nature. Visitors are meant to enjoy constantly shifting views as they stroll along the paths (Chen, 1984; Ji, 1988; Johnston, 1991; Liu, 1993). We attempted to designate relatively homogeneous sections in terms of compositions of various landscape materials (Chen et al, 2009). We studied the site plan and aerial photos first and identified key spots where the panorama view may change substantially. We then decided at the site whether those spots we had identified on the plan reflected significant variations of landscape materials in the view. Finally, we took panorama views based on the best locations identified. It was assumed that views from roads and paths were those most likely to be seen by the largest number of people (Chen et al, 2009), and our photographs were mainly taken from these locations.

The second criterion was the distance from the photographer to the subject, because distance may affect a visitor's overall feeling of the site. A viewing distance of $20-100 \mathrm{~m}$ was set. The range of distance allows a view to have foreground, mid-ground and background, which are important in Chinese landscape painting and landscape scenery (Chen et al, 2009). The photographs showed broad overall views, instead of focusing on detailed elements.

The third criterion was to illustrate all the major features a site possessed within distinctive areas. Distinctive areas are often those for which the gardens are best known and those that visitors tend to patronize. They usually have greater influence on visitors' perception of the garden than other site views. For example, an important design technique, Borrowed Landscape, was used in the Humble Administrator's Garden, with a view of North Temple Tower, which is outside the garden, borrowed to serve as a focal point. On account of its significance, this view was chosen in the analysis. In addition, when the site contains landmark features such as a pagoda or a tower, views containing these landmarks were also included in the analysis. Examples include the pagoda in the North Sea, Fang Ta Park and the modern steel tower in Shipyard Park.

Some other important views were also included if they reflected certain design purposes, such as to manipulate the visitor's feelings. For example, in one of the scholars' gardens, the Lingering
Garden, a design technique called Depth and Sequence is used. Visitors proceed through a dark meandering corridor before suddenly being exposed to a bright and expansive lake view. The Lingering Garden is most famous for this lake view, and hence we included it in the analysis.

Another consideration was the number of photographs that should be analyzed to fully represent the site. Depending on the site size, and based on the above criteria, we chose to analyze 5-20 samples from our image pool for each site. These sample sizes allowed us to average the landscape material coverage to minimize the bias found in any one photograph. For example, for the smallest site, Nanjing Road Plaza, we used five photographs. For another large imperial garden example, Garden of Perfection and Brightness (Yu Ming Yuan), we analyzed 20 images.

To briefly examine what minimal number of images is adequate to demonstrate the composition of any given site, we compared results from five sites in which we varied the number of images studied. Using the Humble Administrator's Garden as an example, we randomly chose three, four and five images from the selected samples, and we averaged the percentage of each landscape material. The results showed that both the percentages and the rankings remain relatively constant. We then proceed with the analysis of other sites.

\section{Landscape element measurement}

We maintained the same five landscape elements (water, rock, pavement, building and planting) as $\mathrm{Wu}$ (1999) has used for two reasons. First,

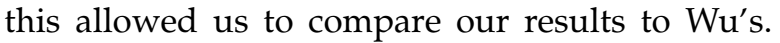
Second, we found that site features of any significant size could be categorized into one of these elements (Keswick, 1978; Johnston, 1991; Liu, 1993; Valder, 2002). The only landscape element that was not easily placed into one of the five categories was site amenities, such as light fixtures, bollards and other very small features, many of which sit on pavement. Given the scale of our analysis, these objects would account for less than one-tenth of 1 per cent of the area coverage in a plan and less than 1 per cent in a view. Thus, we suggested that they were not substantial enough to alter our variables from those proposed by Wu (1999).

In plan analysis, we sometimes found it difficult to locate the position or identify the 

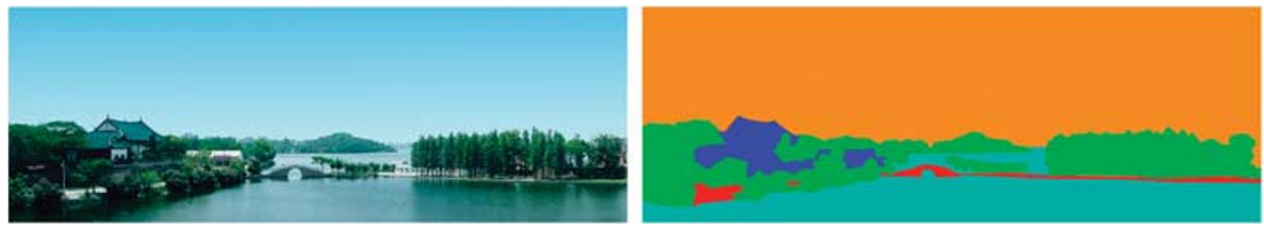

Figure 6: Left: Perspective view of a sample garden (Qing Tai Park, Wuhan). Right: Same view masked for landscape element analysis in Photoshop and GIS. Photo by Bo Yang.

boundary of some landscape elements. This was especially true for rock and water. Rock was sometimes hard to delineate in plan because of the plan resolution. We developed some methods to identify the location and approximations for the amount of rock. For example, in an imperial garden called Garden of Perfection and Brightness (Yuan Ming Yuan), the best plan available does not show rock, and this garden was ruined in the nineteenth century, leaving only relic elements (Lan, 2000; Fu et al, 2002). In such cases, we identified the location and estimated the amount of rock via other sources such as historic paintings depicting the original designs. ${ }^{10}$ In the analysis of this garden, when it was hard to differentiate the edge from water, we again used historical paintings (usually in perspective) to identify the location in plan, and approximate the amount of rock using the scale given in the plan. There are 40 historical paintings for Yuan Ming Yuan, and several different versions exist today. Those paintings were cross-referenced to best estimate the original design. However, this method might still under or overestimate the percentage for rock because we could not fully capture this element.

Another element that was difficult to analyze was water. Our method may have underestimated its percentage in some modern park examples. For example, a modern urban park called Qing Tai Park holds a lake, which is adjacent to a river. In order to define the boundary of the lake, the bridge and the shorelines on the plan were used as a site boundary to arbitrarily separate the lake from the river, realizing that these two water bodies are inherently connected. This resulted in only a portion of a large lake being put into the calculation. In contrast, at the imperial Summer Palace, all of Kunming Lake was calculated because the lake is contained within the site.

For both plans and perspective photographs, we examined the percentage areas devoted to each of the five landscape elements. We used Photoshop CS, a common image processing software program, to manually digitize and mask
Table 3: Percentage coverage based on new analyses of plans

\begin{tabular}{lccrcc}
\hline & Planting & Water & Rock & Architecture & Pavement \\
\hline Imperial Garden & 41 & 43 & 2 & 4 & 11 \\
Scholars' Garden & 24 & 25 & 14 & 16 & 21 \\
Modern Park & 57 & 23 & 2 & 4 & 14 \\
Modern Plaza & 40 & 11 & 0 & 1 & 48 \\
\hline
\end{tabular}

each landscape element with a different color (Clay and Marsh, 1997, 2001; Stamps, 2001; Chen et al, 2009). The images were then incorporated into ArcView GIS software to quantify the grid cells devoted to each element (Figure 6). Grid cell counts were used to determine the percentage coverage for each element (Stamps, 2001; Chen et al, 2009).

\section{Results}

\section{Comparison of plans}

In plan analysis, the ranking of the five elements were the same for imperial gardens and scholars' gardens, though the values varied. In addition, the percentage values for modern parks were close to imperial gardens (Table 3). ${ }^{11}$ Modern parks were found to have less water than imperial gardens, but this could be attributed to the procedures we used to delineate the plans, as water edges in urban parks were often hard to define (such as the aforementioned Qing Tai Park). It was noteworthy that modern plazas were dissimilar to the other three site types. The two dominant elements in plazas were planting and pavement, with pavement accounting for nearly half of the site areas in plazas.

Results of plan analysis were very close to Wu's for scholars' garden, both in ranking and individual percent values (Table 4). ${ }^{12}$ However, our results showed substantially less rock, but more water in modern parks. The reason for this may be because our study used, on average, largerscale urban parks than Wu did. These larger sites 
Table 4: Percentage coverage based on analyses of plans (revised data based on $\mathrm{Wu}, 1999$ )

\begin{tabular}{lcccccc}
\hline & Planting & Water & Rock & Architecture & Pavement \\
\hline Scholars' Garden & 19 & 23 & 17 & 20 & 21 \\
Modern Park & 55 & 10 & 14 & 6 & 15 \\
\hline
\end{tabular}

Table 5: Percentage coverage based on analyses of perspective views (average of five sample images)

\begin{tabular}{lcrrrr}
\hline & Planting & Water & Rock & Architecture & Pavement \\
\hline Imperial Garden & 50 & 24 & 2 & 12 & 11 \\
Scholars' Garden & 34 & 28 & 16 & 15 & 7 \\
Modern Park & 56 & 18 & 1 & 8 & 16 \\
Modern Plaza & 54 & 3 & 0 & 4 & 39
\end{tabular}

reduced the percentage of rock and indirectly increased that of the other elements. ${ }^{13}$

In sum, our plan comparisons showed consistency with $\mathrm{Wu}^{\prime} \mathrm{s}$. Further, our results demonstrated that modern parks and imperial gardens, the two new categories we added, had consistent similarities. Finally, modern plazas were a distinct 'exotic' urban landscape type compared to the traditional models.

\section{Comparison of perspective views}

Measuring perspective views for all the five landscape elements, modern parks were close to imperial gardens in percent coverage for all elements, giving results similar to those found in plan analyses (Table 5). In addition, the differences between modern parks and imperial gardens were far less in perspective views than in plans. The difference range in perspective views is 12 per cent, whereas the range is 36 per cent in plans. For the three categories - imperial gardens, scholars' gardens and modern parks - the top-two landscape values remained as planting and water. Perspective view analyses further demonstrated that there were clear distinctions between modern plazas and the other three types for all landscape elements except planting. ${ }^{14}$

We had hypothesized that perspective views were a better basis for study than plans. The visual impacts of the two-dimensional and three-dimensional landscape elements were quite different in views than in plans, because trees, shrubs and other three-dimensional elements create more spatial differentiation. Across the
Table 6: Comparison of two-dimensional and three-dimensional landscape elements of four open space types

\begin{tabular}{lcc}
\hline Type & $\begin{array}{c}\text { 2D elements } \\
\text { Total } \%^{\mathrm{a}}\end{array}$ & $\begin{array}{c}3 \text { D elements } \\
\text { Total }^{\mathrm{b}}\end{array}$ \\
\hline $\begin{array}{l}\text { Imperial Garden } \\
\text { Plan }\end{array}$ & 53 & 47 \\
$\quad$ Perspective & 35 & 65 \\
Scholars' Garden & & \\
$\quad$ Plan & 46 & 54 \\
Perspective & 35 & 65 \\
Modern Park & & \\
$\quad$ Plan & & \\
Perspective & 37 & 63 \\
Modern Plaza & 34 & 65 \\
Plan & & \\
Perspective & 59 & 51 \\
\hline
\end{tabular}

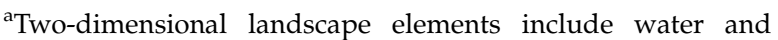
pavement.

bThree-dimensional landscape elements include planting, rock and architecture.

four site categories, percentages of two-dimensional elements decreased and three-dimensional elements increased from plan to perspective (Table 6).

As Table 6 shows, two-dimensional design elements, such as paving, clearly dominate for all four site types in plans. The reverse is true when three-dimensional elements such as trees and buildings are evaluated using photographic scenes. This distinction is clearly because of the effects of perspective on what is seen versus what is obscured and distorted in perspective. In the plan, trees and other upright elements cover a reduced area of the overall site, whereas in views, those upright elements in the fore and middle ground cover much of the middle and background surface materials. Although upright, three-dimensional elements diminish in size as they retreat from the viewer, the amount of distortion in the ground plane, known as foreshortening, makes the apparent size of flat twodimensional elements shrink in apparent size even faster. Interestingly, modern parks show the least differences in percentages, even though they do follow the overall pattern. One reason for this is that some modern parks include large plaza-like areas and often large open grassed areas, thus reducing the impact of the three-dimensional elements present.

In examining the percentage increase from plan to perspective for three-dimensional elements, 
the magnitude of increase, ranked from high to low, is modern plaza, imperial garden, scholars' garden and modern park. This confirms our hypothesis that modern plazas overemphasize two-dimensional elements on the ground plan. Although in the plan the percentage of planting appears to be high, it does not provide much spatial differentiation in the three-dimensional perspective views, as much of the planting is grass, groundcover or low shrubs.

\section{Discussion: Revelation from the Traditional Models}

Perspective analyses rather than plan analyses suggested that there are close similarities between the landscape designs of traditional and modern models. This confirmed one of our hypotheses that perspective view is a better type of document in this kind of visual assessment study. We believed that plans quantify the entire ground surface without considering spatial differentiation created by three-dimensional elements such as trees. Perspective views more closely approximated the three-dimensional human experience, which backed up the link between Chinese landscape painting and their use as inspiration for actual landscape design.

The perspective view comparisons also supported another hypothesis that there is a traditional model - imperial gardens - that could serve as the design inspiration for modern open space design in China. Although there can be significant differences between imperial gardens and modern open spaces, the similarities in use far overshadow those differences. Imperial gardens were intended to be used as recreation grounds by large numbers of people, certainly hundreds and perhaps thousands at one time. While these people were royals, nobles and courtiers, they certainly shared general recreational goals with the contemporary public: they wanted to walk, play group games, sit and talk in beautiful scenery, ride on the water, fish, engage in contemplation, and picnic. The imperial gardens were designed to accommodate numerous users engaging in different activities at the same time. They were large, had different types and scales of features, had numerous spaces distinct from each other, and had an extensive, hierarchical path system. Most, if not all, of these features are shared by modern parks. Thus, the imperial garden, not surprisingly, can serve as a model for their modern public counterpart.

Some more limited similarities between urban parks and scholars' gardens were also noted. These similarities appear to result primarily from cultural preferences for certain types of features, particularly large ponds and rocks, as well as the general use of asymmetrical compositions. In addition, the scholars' gardens are an iconic type in both Chinese and foreign perceptions of traditional landscapes. They are much smaller than imperial gardens, making them easier to mimic and serve as models for some smaller spaces in modern open spaces. Thus, traditional sites seemingly already have been used as design models, perhaps intuitively, based on Chinese aesthetic preference or, in a few cases by Westerners' experience of what is considered the most typical traditional landscape type.

Our results also demonstrated that modern plazas are, in China, a distinct type of designed open space compared with modern parks, scholars' gardens and imperial gardens. Although plazas existed in China well before the nineteenth and twentieth centuries, these spaces lacked the types of design amenities that modern users anticipate, and often were simply large paved spaces. European introduction of RenaissanceBaroque-inspired geometric layouts having ground plane design emphasis and very few three-dimensional elements seem to have been widely accepted in China. This type of design introduced more detail into the scene, especially low-growing plants, but largely retained the visually open plan, a trait with which the Chinese are familiar.

Another marked difference between modern and traditional landscape designs emerged. This is the difference in the amount of rock, especially the large amount found in scholars' gardens, and its almost complete absence in both modern parks and plazas. In addition, when modern designs include rock, it is often used primarily as a geological material, not selected for its aesthetic qualities, as in traditional landscapes. There are a number of explanations for these differences: (1) a conscious effort to give new parks a distinctive 'modern' look, thus avoiding use of traditional rock types and compositions; (2) limited availability of the preferred artistic rock types; (3) the cost of rock, which precludes use of the more artistic examples; and (4) reduced connoisseurship of rocks and rock compositions 
in modern fast-paced society than in the past (Dillingham, 1991; Wu, 1999).

There were two types of elements, urban furniture and sculptures (other than rocks), which were not substantially included in this visual assessment study. These elements were not typically found in traditional landscapes, but entered Chinese gardens via the Europeanintroduced City Beautiful movement. Large urban sculptures and urban furniture can be found today in many urban plazas in China, and some might consider them analogous to rock compositions in traditional scenes. But the ways in which they are used appear to have been Westerninspired. They are based on Western-originated artistic styles, often use inorganic human-made materials and, although often asymmetric in internal form, are set in the landscape in a radial or bilaterally symmetric position, such as the center of a circle or along a sight-line.

Among the urban plaza examples in this study, only the Nanjing Road Plaza has a small terraced fountain, which sits in the center of the pavement. This fountain was categorized as an architectural material in the analysis. The remainder of the urban plaza examples we chose did not contain massive sculpture or urban furniture. In future studies, we shall include samples that have more urban furniture and sculptures and evaluate their visual impacts.

\section{Conclusion}

Results of our multi-method study confirmed to varying degrees each of our three hypotheses. There is a Chinese prototype or model - the imperial park - that can serve effectively as a model for the modern public park. This is largely because of general similarities in scale and the preferred recreational uses incorporated into each site type design.

In general, we found that there are fewer differences between modern and traditional public open spaces than the earlier researcher Wu had concluded, at least among imperial parks, scholars' gardens and modern parks. Modern plazas remain a discrete type that shares a few characteristics with older Chinese plazas, but appear to be a site type that is most influenced by Western models.

The type of data used to analyze the percentage of landscape element has been demonstrated to have an impact on the results. Plans were found to overemphasize ground plane materials, whereas perspective views could better represent the seen reality of human experience. The use of perspective views also relates to the way in which traditional Chinese open spaces were designed based on inspiration from landscape painting. Thus, the hypothesis that perspective views would produce more accurate results than plans was supported.

As we recognize that each data type presents its own problems, future study will need to include survey instruments to investigate how people perceive different materials in different types of open space. More replicable methods for view selections should also be developed. Future study should also include more samples, plazas in particular, which take into account sculpture elements. A more detailed literature review and historical study of traditional Chinese plazas should also be conducted to elucidate their relationship to the nineteenth- and twentiethcentury evolution of plaza design, a subject that is not well treated in the English-language literature.

By reexamining and reinterpreting the imperial garden model, our study suggested that parks and plazas can be created that are distinctive to China, suit Chinese aesthetic preferences and provide sustainable counterpoints to the densely built-up urban environments in which most Chinese citizens live. The Chinese have traditional models that provide them with beautiful scenic landscapes, which have been demonstrated to reduce stress (Ulrich, 1986). They can also draw upon the Euro-American model of the plaza for intensely used urban sites. Unfortunately, in the past the open plaza model, in which two-dimensional patterned surfaces predominated, has been too widely used in inappropriate settings, creating spaces that are underused and uncomfortable for users (Yu and Li, 2003; Yu and Padua, 2007). It is within the ability of designers to fuse these two design traditions, the Chinese and the Euro-American, to create a modern hybridized form that will increase the attractiveness and functionality of the large number of public open spaces to be created in China in the future. Given the rapidity of urban development in contemporary China and the large number of people to be affected, urban open space infrastructure study such as this will contribute to an understanding of the cultural needs and preferences in such spaces and provide long-term benefits to the Chinese. 


\section{Notes}

1 All Chinese terms are given in Mandarin and based on Pin Yin transliterations.

2 For the purposes of this article, we are using the terms 'Western' and 'European' for gardens and other landscapes that follow the Renaissance and Baroque patterns of design, particularly those approaches initiated in Italy and France. We recognize that European design was diverse over its long history. But what would have been novel to the Chinese was the formality of these styles. The later Landscape Gardening approach was, of course, based in part on Chinese design, and therefore would not have seemed noteworthy to the Chinese. In addition, it is important to recognize that the Chinese did use some formal, geometric layouts in their city planning (Beijing and Changan among others) and palace planning (Forbidden City as an example), but this was based on a different major rationale, which was an expression of status and role hierarchy.

3 The inference of these two Chinese terms is that yuan is a planted idealized landscape, whereas guangchang is a more practical unplanted area. We used the English term garden to imply a planted space that is originally intended to be private and intimate. Park implies a planted public space, and plaza means a more structured and intensively used public space.

4 This type of spatial structure was not unknown in China but typically was found in the organization of urban-scale places such as the imperial palace referred to as the Forbidden City in Beijing.

5 This emphasis on Chinese use of formal, geometric European spatial arrangement is not intended to suggest that this was the only type of inspiration that has come from the West. Rather, it was what the Chinese viewed as new and 'modern' that they adopted for a large part of the twentieth century. Toward the end of the century, design inspiration largely came from contemporary sources.

6 Officials participating in these tours usually visited renowned metropolises or places such as Washington DC, Las Vegas, Disneyland, Paris, Versailles and Rome (Yu and Padua, 2007).

7 This applies to all site types except imperial gardens, where we only used four examples, because of the limited number of relevant examples. We acknowledge that our choice of sites is subjective and in not a random sample. Given the number of sites of most types available, a truly random sample would seem to be impossible for this study.

8 Books we used included: Chen and Yu (1986), Cheng (1998a, b), Yoshikawa (1990), Liu (1993), Fu (2002), and Yu and Pang (2003).

9 We acknowledge that no matter how many criteria we selected, the viewpoints used remain subjective. Given the individuality of designs, a truly systematized approach (such as using views from the main entry for each site) would not necessarily produce representative views of the sites as a whole. Although we also acknowledge that the view selection is not reproducible in the scientific sense, we believe that application of the criteria would lead to the selection of similar views and thus yield similar results.

10 We used both color and black and white illustrations of the Garden of Perfection and Brightness (Yuan Ming Yuan) to identify the rock location and estimate its per cent coverage. The books we used were Sirén (1949),
Danby (1950), Lan (2000), Fu et al. (2002), Lou (2003) and Chung (2004).

11 Traditional Chinese plazas were almost exclusively paved areas, whether the pavement was permeable or impermeable. As examples of this dominance of pavement are Tiananmen Square, the courtyards of the Forbidden City and even the small landing plazas found along canals in Suzhou.

12 In Wu (1999), per cent coverage is, in part, an artifact of the way in which she measured and calculated her data. When we totaled the five landscape element percentages, the value often exceeded 100 per cent. We believed these errors were not rounding errors and could be attributed to two factors: typographic error or 'double-counting' some landscape elements. Just as we observed in our analyses, some elements such as rock, planting and pavement were hard to separate when looking at plans. Wu may have recognized this issue, but presented the data as they turned out. We assumed that $\mathrm{Wu}^{\prime} \mathrm{s}$ data on individual landscape elements are correct. We made revisions to her data by summing up her percentages and divided that total, which is over 100 per cent, by the percentage of each element. This then reset all of her percentages to a 100 per cent base. The revised data are presented in Table 4.

13 In comparison, European and American landscapes before the twentieth century tended to utilize rock as a geological material. F. L. Olmsted, Sr. and H. W. S. Cleveland both exposed in situ rocks and incorporated them into their site plans - Olmsted using a large outcrop to create spaces at the Ramble in Central Park and Cleveland using glacial erratics as entry markers and focal points in Gloucester, MA cemetery. In the twentieth century, the Asian approach to the use of rock as a sculptural, symbolic material has been extensively adopted.

14 Planting included all types of plant cover. Two-dimensional plantings (grass) predominated in modern plazas, whereas three-dimensional plants (trees and shrubs) were in the majority in both traditional site types and modern parks. The visual impacts of the two-dimensional and threedimensional plants were quite different, with grasses being much like a green pavement, whereas trees and shrubs creating more spatial differentiation.

\section{References}

Arriaza, M., Canas-Ortega, J.F., Canas-Madueno, J.A. and Ruiz-Aviles, P. (2004) Assessing the visual quality of rural landscapes. Landscape and Urban Planning 69: 115-125.

Boyd, A. (1962) Chinese Architecture and Town Planning 1500B.C.-A.D.1911. London: Tiranti.

Chen, B., Adimo, O.A. and Bao, Z.Y. (2009) Assessment of aesthetic quality and multiple functions of urban green space from the users' perspective: The case of Hangzhou Flower Garden, China. Landscape and Urban Planning 93: 76-82.

Chen, C.Z. (1984) On Chinese Garden, (in Chinese) Shanghai, PRC: Tongji University Press.

Chen, L.F. and Yu, S.L. (1986) The Garden Art of China. Portland, OR: Timber Press.

Chen, Z.L. (1999) Dilemma and solution for urban parks: Case study of Shanghai. (in Chinese, title translated by authors) Chinese Landscapes 15(3): 37-39. 
Cheng, L.Y. (1998a) Ancient Chinese Architecture: Private Gardens, Translated by L. Zhang. New York: Springer-Verlag Wien.

Cheng, L.Y. (1998b) Ancient Chinese Architecture: Imperial Palaces, Translated by L. Zhang. New York: Springer-Verlag Wien

Cheng, Y. (2003) Pre-modern and modern urban morphology evolvement of Suzhou (in Chinese, title translated by authors). Urban Planning Forum 6: 62-71.

Chung, A. (2004) Drawing Boundaries: Architectural Images in Qing China. Honolulu, HI: University of Hawaii Press.

Chung, W.N. (1982) Art of Chinese gardens. Hong Kong: Hong Kong University Press.

Clay, G.R. and Marsh, S.E. (1997) Spectral analysis for articulating scenic color changes in a coniferous landscape. Photogrammatic Engineering and Remote Sensing 63(12): 1353-1362.

Clay, G.R. and Marsh, S.E. (2001) Monitoring forest transitions using scanned ground photographs as a primary data source. Photogrammatic Engineering and Remote Sensing 67(3): 319-330.

Danby, H. (1950) Garden of Perfect Brightness: The History of the Yuan Ming Yuan and of the Emperors Who Lived There. London: Williams and Norgate.

Dillingham, C.L. (1991) Stepping out of the Scholar's Garden. Habitat International 3: 67-72.

Foreign Language Teaching and Research Press, Editorial Division. (1995) A Modern Chinese-English Dictionary. Beijing, PRC: Foreign Language Teaching and Research Press.

Fu, X.N., Guo, D.H., Liu, X.J., Pan, G.X., Qiao, Y. and Sun, D.Z. (2002) Chinese Architecture, Translated by N.S. Steinhardt. New Haven, CT: Yale University Press.

Geng, H. (1999) The analysis of the main problems came from the urban renewal of the Chinese major cities in the 1990s. (in Chinese, title translated by authors) City Planning Review 7: 13-17.

Gothein, M.L. (1979) A History of Garden Art, Vol. 1. New York: Hacker Art Books.

Ji (Chi), C. (1988) Graft of Gardens, Translated by A. Hardie. New Haven, CT: Yale University Press.

Johnston, S.R. (1991) Scholar Gardens of China: A Study and Analysis of the Spatial Design of the Chinese Private Garden. Cambridge: Cambridge University Press.

Keswick, M. (1978) Chinese Garden: History, Art \& Architecture. New York: Rizzoli International Publications.

Lan, P.J. (2000) Yuanmingyuan Garden. Beijing, PRC: Foreign Languages Press.

Leitão, A.B. and Ahern, J. (2002) Applying landscape ecological concepts and metrics in sustainable landscape planning. Landscape and Urban Planning 59: 65-93.

Liu, D.Z. (1993) Chinese Classical Gardens of Suzhou. New York: McGraw-Hill.

Lou, Q.X. (2003) Chinese Gardens, Translated by L. Zhang and H. Yu. Beijing, PRC: China Intercontinental Press.

Morris, E.T. (1983) Gardens of China: History, Art, and Meanings. New York: Charles Scribner's Sons.
Newton, N. (1971) Design on the Land: The Development of Landscape Architecture. Cambridge, MA: The Belknap Press of Harvard University Press.

Peng, Y.G. (1986) Analysis of the Traditional Chinese Garden, (in Chinese) Beijing, PRC: China Architecture and Building Press.

Shuttleworth, S. (1980) The use of photographs as an environmental presentation medium in landscape studies. Journal of Environmental Management 11: 61-76.

Sirén, O. (1949) Gardens of China. New York: The Ronald Press Company.

Stamps, A.E. (2001) Evaluating enclosure in urban sites. Landscape and Urban Planning 57: 13-24.

Sun, X.X. (1986) The aesthetics and education of landscape planning in China. Landscape and Urban Planning 13: 481-486.

Suzhou Local History Academy. (1995) Suzhou History (in Chinese, title translated by authors). Nanjing, PRC: Jiangshu People's Press.

Thacker, C. (1979) History of Gardens. Great Britain: London Editions.

Ulrich, R. (1986) Human responses to vegetation and landscapes. Landscape and Urban Planning 13: 29-44.

Valder, P. (2002) Gardens in China. Portland, OR: Timber Press.

Wong, Y.T. (2001) A Paradise Lost: The Imperial Garden Yuanming Yuan. Honolulu, HI: University of Hawaii' Press.

$\mathrm{Wu}, \mathrm{L}$. (1996) On the physical planning and the planning system of the Chinese cities. In: L. Wu (ed.) Collection on Urban Planning Studies, (in Chinese) Beijing, PRC: China Architecture and Building Press, pp. 50-59.

Wu, W. (1996) Fang Ta Yuan design review. (in Chinese, title translated by authors) Urban Planning Forum 3: 16-20.

$\mathrm{Wu}$, X.Y. (1999) Comparison of Chinese traditional garden and contemporary park (in Chinese, title translated by authors). Chinese Landscapes 15: 66-69.

Xie, Y.C. and Costa, F.J. (1993) Urban planning in socialist China: Theory and practice. Cities 10(2): 103-114.

Yang, H.X. (1982) The Classical Gardens of China: History and Design Techniques, Translated by H.M. Wang. New York: Van Nostrand Reinhold.

Yoshikawa, I. (1990) Chinese Gardens. Tokyo, Japan: Graphicsha Publishing Company.

$\mathrm{Yu}$, K.J. and Li, D.H. (2003) City Landscapes: Communication with Mayors (in Chinese, title translated by authors). Beijing, PRC: China Architecture and Building Press.

Yu, K.J. and Padua, M.G. (2007) China's cosmetic cities: Urban fever and superficiality. Landscape Research 32(2): 255-272.

Yu, K.J. and Pang, W. (2003) The Culture Being Ignored and the Beauty of Weeds: the Regenerative Design of an Industrial Site, the Zhongshan Shipyard Park, (in Chinese) Beijing, PRC: China Architecture and Building Press.

Zhou, W.Q. (2004) Cultural background for the development of Chinese classical landscape architecture. (in Chinese) Chinese Landscapes 9: 59-62.

Zhu, J. (1992) Chinese Landscape Gardening. Beijing, PRC: Foreign Languages Press. 